\title{
Standardized Unexpected Earnings In The U. S. Technology Sector
}

H. Christine Hsu*** (E-mail: Chsu@csuchico.edu), California State University, Chico

\begin{abstract}
Earnings surprise occurs when the firm's reported earnings per share deviates from the street estimate. This study shows that earnings surprises are useful in identifying portfolios that yield excess returns in the U.S. tech sector. The tech portfolios with the most positive earnings surprises outperformed the tech portfolios with the most negative earnings surprises in terms of both mean and median returns in the U.S. stock market. The study demonstrates that arbitrage profits could be generated if investors bought (short sold) the tech stocks with the highest earnings surprises (the lowest) two or three months after the end of the quarter. The study demonstrates that this trading strategy is most effective when fewer rather than more financial analysts follow the firms.
\end{abstract}

\section{Introduction}

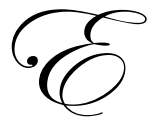

arnings surprise occurs when the firm's reported earnings per share deviates from the street estimate or the analysts' consensus forecast. The unexpected earnings have been found to be useful in predicting abnormal stock returns. The investment implications of the size and sign of the unexpected earnings in global equity markets are well addressed in recent years. For example, Sultan (1994) finds that the unexpected earnings can be used as a discriminator between stocks that performed relatively well and stocks that performed relative poorly in Japan. Brown and Jeong (1998) show that an earnings surprise predictor is effective in selecting stocks from S\&P 500 firms. Dische and Zimmermann (1999) report that abnormal returns can be earned from the portfolio of the Swiss stocks exhibiting the most positive earnings revision. Conroy, Eades and Harris (2000) find that stock prices are significantly affected by earnings surprises in Japan. Mozes (2000) shows that the strategy of buying stocks on the basis of positive forecasted earnings surprises is more profitable for value firms than for growth firms. Bird, McElwee and McKinnon (2000) provide insights into how to identify investment opportunities based on earnings surprises and highlight the extent to which the opportunities differ across countries. Hsu (2001) demonstrates that it is profitable to take a long position in the portfolios with the highest earnings surprises and a short position in the portfolios with the lowest earnings surprises in the Asia/Pacific equity market. Levis and Liodakis (2001) conclude that positive and negative earnings surprises have an asymmetrical effect on the returns of low- and high-rated stocks in the U.K. However, not much on the subject is documented for specific industry sectors. The objective of this study is to contribute to the literature by adding this missing piece. The focus is on the U.S. technology sector as it has attracted significant public interest in recent years. This paper first examines if a trading strategy on the basis of earnings surprises worked in the U.S. tech sector. Then it investigates if the strategy worked better for firms followed by fewer rather than more financial analysts.

\footnotetext{
${ }^{*}$ A version of this article is published in Business Quest 2002, http://www.westga.edu/ bquest/2002/\#research.

${ }^{* *}$ The author is grateful for the contribution of Institutional Brokers Estimate System, Inc. for providing the earnings expectations data used in this study. Readers with comments or questions are encouraged to contact the author via email.
} 


\section{Data And Analysis}

This study is based upon a sample of the U.S. tech firms with fiscal year ending in March, June, September or December compiled in I/B/E/S History database for the period $1994-2000$. To eliminate firms with inactive trading, the sample includes only those firms followed by at least three financial analysts. The sample universe consists of roughly 270 tech firms in 1994, growing to 500 firms in 2000, resulting in 7966 stock-quarter observations for the analysis.

To see if earnings surprises can be used to construct a trading strategy, the relationship between earnings surprises and stock performance is examined. Standardized unexpected earnings, SUE, is used to measure earnings surprise:

$\mathrm{SUE}_{\mathrm{Q}}=\left(\mathrm{A}_{\mathrm{Q}}-\mathrm{F}_{\mathrm{Q}}\right) / \mathrm{SD}_{\mathrm{Q}}$

...where $\mathrm{SUE}_{\mathrm{Q}} \quad=$ quarter $\mathrm{Q}$ standardized unexpected earnings

$\mathrm{A}_{\mathrm{Q}} \quad=$ quarter $\mathrm{Q}$ actual earnings per share reported by the firm

$\mathrm{F}_{\mathrm{Q}} \quad$ = quarter $\mathrm{Q}$ consensus earnings per share forecasted by analysts in quarter $\mathrm{Q}-1$

$\mathrm{SD}_{\mathrm{Q}} \quad=$ quarter $\mathrm{Q}$ standard deviation of earnings estimates

SUE measures the earnings surprise in terms of the number of standard deviation above or below the consensus earnings estimate. The absolute value of SUE measures the degree of unexpected earnings and the sign of SUE indicates whether the unexpected earnings are above or below the consensus estimate. That is, the greater the positive SUE the greater the earnings surprise above the earnings estimate while the smaller the negative SUE the greater the earnings surprise below the earnings estimate. There's no earnings surprise when SUE equals zero; the actual earnings per share is in line with the consensus earnings estimate.

At the end of each quarter from 1994.4 to 1999.4, firms are ranked on the basis of their SUE scores and categorized into one of the five portfolios. The portfolio ranked the highest on SUE contains firms with SUE $\geq 5$ and the portfolio ranked the lowest on SUE contains firms with SUE $\leq-5$. The main interest of the analysis is on these two extreme portfolios.

The 3-month holding period rate of return, $\mathrm{R}$, is then calculated as the sum of the stock's dividend yield and capital gains yield for each firm:

$\mathrm{R}_{\mathrm{t}+3}=\left[\mathrm{DIV} \mathrm{V}_{\mathrm{t}+3} / \mathrm{P}_{\mathrm{t}}\right]+\left[\left(\mathrm{P}_{\mathrm{t}+3}-\mathrm{P}_{\mathrm{t}}\right) / \mathrm{P}_{\mathrm{t}}\right]$

...where $\mathrm{Rt}+3 \quad=$ three-month holding period rate of return, transaction made in month $\mathrm{t}$

$\mathrm{DIVt}+3=$ dividends on common stock during the three-month holding period

$\mathrm{Pt}+3=$ month $\mathrm{t}+3$ price of stock

$\mathrm{Pt} \quad=$ month $\mathrm{t}$ price of stock

Table 1 summarizes the descriptive statistics of the 3-month holding period returns for the portfolios ranked the highest and the lowest on SUE. The highest SUE portfolios outperformed the lowest SUE portfolios in terms of both mean return and median return in all 20 quarters when the stock transactions were made at the ending month of SUE quarter for the period 1995.1 to 1999.4. Figure 1 shows the quarterly mean returns for the two portfolios over the quarters 1995.2 to 2000.1. The differences between the two portfolios' mean (median) returns ranging from $12.7 \%$ to $62.3 \%$ are statistically significant for all 20 investment periods. The implication is that going long in the portfolios with SUE $\geq 5$ and going short in the portfolios with SUE $\leq-5$ can generate handsome arbitrage profits in every single quarter from 1995.2 to 2000.1. As SUE information is not available at the end of the SUE quarter in practice, predicting SUE is an important task for fund managers and investors. 
Table 1

Quarterly Return ${ }^{\text {a }}$ Statistics Of The Portfolios Ranked The Highest And The Lowest On SUE

\begin{tabular}{|c|c|c|c|c|c|}
\hline SUE Quarter & & SUE $\geq 5$ & SUE $\leq-5$ & Spread & T-Statistics \\
\hline \multirow[t]{4}{*}{95.1} & Mean & 0.196 & -0.051 & 0.247 & $(3.996) * * *$ \\
\hline & Median & 0.198 & -0.057 & 0.255 & $(4.545)^{* * *}$ \\
\hline & Standard Deviation & 0.202 & 0.274 & & \\
\hline & Count & 59 & 24 & & \\
\hline \multirow[t]{4}{*}{95.2} & Mean & 0.371 & 0.030 & 0.341 & $(6.229)^{* * *}$ \\
\hline & Median & 0.360 & 0.010 & 0.351 & $(8.885)^{* * *}$ \\
\hline & Standard Deviation & 0.281 & 0.230 & & \\
\hline & Count & 55 & 34 & & \\
\hline \multirow[t]{4}{*}{95.3} & Mean & 0.161 & -0.195 & 0.356 & $(4.275) * * *$ \\
\hline & Median & 0.074 & -0.223 & 0.298 & $(6.611) * * *$ \\
\hline & Standard Deviation & 0.449 & 0.255 & & \\
\hline & Count & 41 & 32 & & \\
\hline \multirow[t]{4}{*}{95.4} & Mean & 0.131 & -0.254 & 0.385 & $(5.623)^{* * *}$ \\
\hline & Median & 0.039 & -0.266 & 0.305 & $(8.287)^{* * *}$ \\
\hline & Standard Deviation & 0.361 & 0.227 & & \\
\hline & Count & 39 & 38 & & \\
\hline \multirow[t]{4}{*}{96.1} & Mean & 0.253 & -0.075 & 0.328 & $(5.580)^{* * *}$ \\
\hline & Median & 0.197 & -0.119 & 0.317 & $(8.457) * * *$ \\
\hline & Standard Deviation & 0.323 & 0.212 & & \\
\hline & Count & 51 & 32 & & \\
\hline \multirow[t]{4}{*}{96.2} & Mean & 0.088 & -0.240 & 0.327 & $(6.904)^{* * *}$ \\
\hline & Median & 0.127 & -0.252 & 0.379 & $(13.309)^{* * *}$ \\
\hline & Standard Deviation & 0.246 & 0.197 & & \\
\hline & Count & 42 & 48 & & \\
\hline \multirow[t]{4}{*}{96.3} & Mean & 0.039 & -0.088 & 0.127 & $(2.267)^{*}$ \\
\hline & Median & 0.016 & -0.065 & 0.081 & $(1.947)^{*}$ \\
\hline & Standard Deviation & 0.278 & 0.267 & & \\
\hline & Count & 55 & 41 & & \\
\hline \multirow[t]{4}{*}{96.4} & Mean & -0.124 & -0.323 & 0.199 & $(3.819) * * *$ \\
\hline & Median & -0.134 & -0.338 & 0.204 & $(4.727) * * *$ \\
\hline & Standard Deviation & 0.220 & 0.237 & & \\
\hline & Count & 57 & 30 & & \\
\hline \multirow[t]{4}{*}{97.1} & Mean & 0.365 & -0.140 & 0.505 & $(7.672) * * *$ \\
\hline & Median & 0.303 & -0.077 & 0.381 & $(9.361)^{* * *}$ \\
\hline & Standard Deviation & 0.401 & 0.241 & & \\
\hline & Count & 60 & 35 & & \\
\hline \multirow[t]{4}{*}{97.2} & Mean & 0.311 & -0.056 & 0.367 & $(6.043)^{* * *}$ \\
\hline & Median & 0.202 & -0.012 & 0.214 & $(5.264) * * *$ \\
\hline & Standard Deviation & 0.350 & 0.266 & & \\
\hline & Count & 60 & 43 & & \\
\hline \multirow[t]{4}{*}{97.3} & Mean & -0.097 & -0.410 & 0.313 & $(7.488)^{* * *}$ \\
\hline & Median & -0.076 & -0.450 & 0.375 & $(11.330)^{* * *}$ \\
\hline & Standard Deviation & 0.220 & 0.209 & & \\
\hline & Count & 74 & 40 & & \\
\hline \multirow[t]{4}{*}{97.4} & Mean & 0.342 & -0.097 & 0.439 & $(7.175)^{* * *}$ \\
\hline & Median & 0.344 & -0.171 & 0.515 & $(10.906)^{* * *}$ \\
\hline & Standard Deviation & 0.309 & 0.331 & & \\
\hline & Count & 63 & 49 & & \\
\hline
\end{tabular}




\begin{tabular}{|c|c|c|c|c|c|}
\hline \multirow[t]{4}{*}{98.1} & Mean & -0.006 & -0.296 & 0.290 & $(6.964) * * *$ \\
\hline & Median & -0.022 & -0.336 & 0.313 & $(10.437) * * *$ \\
\hline & Standard Deviation & 0.251 & 0.216 & & \\
\hline & Count & 76 & 52 & & \\
\hline \multirow[t]{4}{*}{98.2} & Mean & 0.011 & -0.414 & 0.425 & $(9.775)^{* * *}$ \\
\hline & Median & 0.001 & -0.405 & 0.406 & $(17.896)^{* * *}$ \\
\hline & Standard Deviation & 0.310 & 0.186 & & \\
\hline & Count & 70 & 67 & & \\
\hline \multirow[t]{4}{*}{98.3} & Mean & 0.333 & -0.028 & 0.360 & $(5.126) * * *$ \\
\hline & Median & 0.279 & -0.070 & 0.348 & $(5.947) * * *$ \\
\hline & Standard Deviation & 0.354 & 0.469 & & \\
\hline & Count & 83 & 64 & & \\
\hline \multirow[t]{4}{*}{98.4} & Mean & 0.251 & -0.089 & 0.340 & $(3.569) * * *$ \\
\hline & Median & 0.137 & -0.122 & 0.259 & $(4.167) * * *$ \\
\hline & Standard Deviation & 0.711 & 0.403 & & \\
\hline & Count & 97 & 42 & & \\
\hline \multirow[t]{4}{*}{99.1} & Mean & 0.292 & -0.057 & 0.350 & $(4.348) * * *$ \\
\hline & Median & 0.207 & -0.100 & 0.308 & $(5.130) * * *$ \\
\hline & Standard Deviation & 0.488 & 0.433 & & \\
\hline & Count & 83 & 52 & & \\
\hline \multirow[t]{4}{*}{99.2} & Mean & 0.338 & -0.112 & 0.450 & $(7.873) * * *$ \\
\hline & Median & 0.273 & -0.191 & 0.463 & $(11.218)^{* * *}$ \\
\hline & Standard Deviation & 0.381 & 0.283 & & \\
\hline & Count & 93 & 47 & & \\
\hline \multirow[t]{4}{*}{99.3} & Mean & 0.610 & -0.013 & 0.623 & $(6.519) * * *$ \\
\hline & Median & 0.433 & -0.058 & 0.490 & $(8.285)^{* * *}$ \\
\hline & Standard Deviation & 0.728 & 0.384 & & \\
\hline & Count & 94 & 42 & & \\
\hline \multirow[t]{4}{*}{99.4} & Mean & 0.578 & 0.132 & 0.446 & $(3.609) * * *$ \\
\hline & Median & 0.562 & 0.001 & 0.561 & $(5.068) * * *$ \\
\hline & Standard Deviation & 0.602 & 0.683 & & \\
\hline & Count & 121 & 38 & & \\
\hline
\end{tabular}

${ }^{\text {a }}$ Stock transactions were made at the ending month of the SUE quarter.

*** Significant at .0005 level.

* Significant at .05 level. 
Figure 1

Quarterly Mean Returns of Portfolios Ranked the Highest and the Lowest on Sue, 1995.2-2001.1

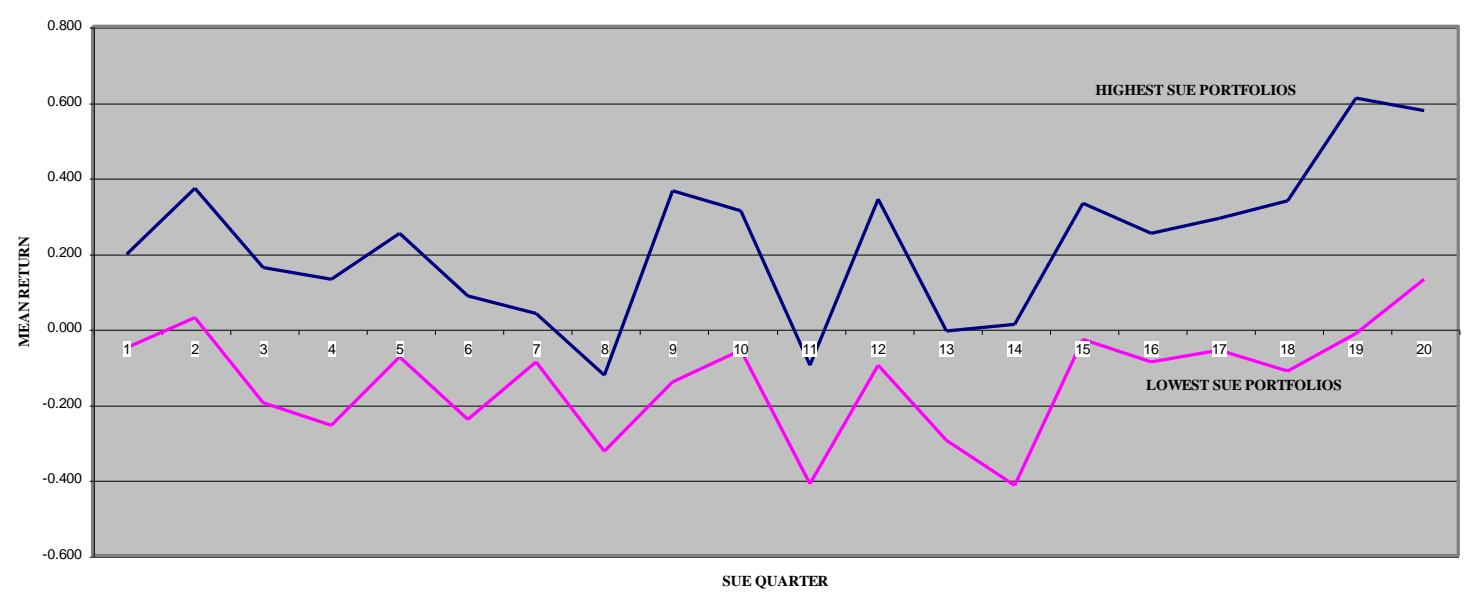

Accurately predicting SUE is extremely rewarding but it's not an easy job, especially for individual investors with limited information. Is trading according to the public information of past SUE still profitable? In practice, firms announce quarterly earnings within two months after the end of the quarter for the first three quarters and within three months after the end of the fourth quarter. To ensure that SUE information is available to the public at the time of the stock transactions, the stocks are bought in May, August, November and March hereinafter in this study. Once again, firms are ranked according to their SUE scores and placed in one of the five portfolios for each of the SUE quarters, 1994.4 - 1999.3. All stocks are held for three months and sold at the end of the 3-month holding period; the reposition of portfolio holdings takes place every three months throughout the 5-year study period. Table 2 shows the holding period return statistics by SUE category. Notice that the portfolios with SUE $\geq 5$ outperformed the portfolios with SUE $\leq-5$ in 18 out of the 20 investment periods in terms of both mean and median returns. The two exceptions are SUE quarters 1996.3 and 1998.4. Also shown in Table 2 is that the higher returns generated by the portfolios are not associated with the higher standard deviations. That is, risk as measured in terms of the dispersion of the returns is not a factor in determining the portfolio return over the 5-year investment horizon in this study. Table 2 suggests that investors could have reaped arbitrage profits if they traded portfolios on the basis of the previous quarter's SUE scores, i.e., bought the highest SUE portfolios and short sold the lowest SUE portfolios every three months.

Table 2

Quarterly Return ${ }^{\text {a }}$ Statistics Of The Portfolios Ranked On SUE

\begin{tabular}{|llllllll|}
\hline $\begin{array}{l}\text { SUE } \\
\text { Quarter }\end{array}$ & & SUE $\geq \mathbf{5}$ & $\mathbf{5}>$ SUE $\geq \mathbf{1}$ & $\mathbf{1}>\mathbf{S U E}>\mathbf{- 1}$ & $\mathbf{- 1} \geq \mathbf{S U E}>\mathbf{- 5}$ & $\mathbf{- 5} \geq \mathbf{S U E}$ & All \\
\hline 94.4 & Mean & 0.152 & 0.121 & 0.156 & 0.159 & 0.020 & 0.136 \\
& Median & 0.186 & 0.128 & 0.134 & 0.137 & -0.033 & 0.137 \\
& Standard Deviation & 0.258 & 0.217 & 0.199 & 0.269 & 0.242 & 0.230 \\
& Count & 40 & 79 & 85 & 40 & 19 & 263 \\
95.1 & Mean & 0.275 & 0.243 & 0.243 & 0.110 & 0.137 & 0.224 \\
& Median & 0.252 & 0.177 & 0.194 & 0.066 & 0.144 & 0.180 \\
& Standard Deviation & 0.241 & 0.359 & 0.308 & 0.221 & 0.241 & 0.300 \\
95.2 & Count & 59 & 84 & 71 & 34 & 23 & 271 \\
& Mean & 0.080 & -0.032 & -0.014 & -0.076 & -0.102 & -0.020 \\
& Median & 0.061 & -0.035 & -0.048 & -0.099 & -0.151 & -0.043 \\
& Standard Deviation & 0.351 & 0.259 & 0.212 & 0.318 & 0.230 & 0.278 \\
\hline
\end{tabular}


International Business \& Economics Research Journal

Volume 1, Number 9

\begin{tabular}{|c|c|c|c|c|c|c|c|}
\hline & Count & 55 & 98 & 71 & 38 & 34 & 296 \\
\hline \multirow[t]{4}{*}{95.3} & Mean & 0.071 & -0.034 & -0.044 & -0.051 & 0.042 & -0.019 \\
\hline & Median & 0.070 & -0.026 & -0.042 & -0.046 & 0.034 & -0.019 \\
\hline & Standard Deviation & 0.244 & 0.335 & 0.217 & 0.255 & 0.257 & 0.276 \\
\hline & Count & 40 & 101 & 83 & 55 & 32 & 311 \\
\hline \multirow[t]{4}{*}{95.4} & Mean & 0.095 & 0.059 & 0.067 & 0.074 & 0.079 & 0.071 \\
\hline & Median & 0.150 & 0.027 & 0.059 & 0.036 & 0.061 & 0.059 \\
\hline & Standard Deviation & 0.290 & 0.275 & 0.259 & 0.315 & 0.237 & 0.274 \\
\hline & Count & 39 & 89 & 104 & 60 & 38 & 330 \\
\hline \multirow[t]{4}{*}{96.1} & Mean & -0.176 & -0.191 & -0.124 & -0.236 & -0.179 & -0.172 \\
\hline & Median & -0.168 & -0.220 & -0.132 & -0.223 & -0.170 & -0.179 \\
\hline & Standard Deviation & 0.223 & 0.251 & 0.269 & 0.192 & 0.211 & 0.243 \\
\hline & Count & 50 & 90 & 115 & 55 & 31 & 341 \\
\hline \multirow[t]{4}{*}{96.2} & Mean & 0.089 & 0.135 & 0.015 & 0.091 & -0.032 & 0.060 \\
\hline & Median & 0.134 & 0.097 & 0.029 & 0.069 & -0.021 & 0.046 \\
\hline & Standard Deviation & 0.265 & 0.329 & 0.271 & 0.340 & 0.259 & 0.301 \\
\hline & Count & 42 & 88 & 116 & 62 & 48 & 356 \\
\hline \multirow[t]{4}{*}{96.3} & Mean & -0.041 & 0.030 & 0.096 & 0.052 & 0.146 & 0.056 \\
\hline & Median & -0.016 & 0.018 & 0.073 & 0.083 & 0.137 & 0.055 \\
\hline & Standard Deviation & 0.287 & 0.289 & 0.294 & 0.271 & 0.368 & 0.300 \\
\hline & Count & 55 & 95 & 111 & 70 & 41 & 372 \\
\hline \multirow[t]{4}{*}{96.4} & Mean & 0.356 & 0.136 & 0.176 & 0.127 & 0.093 & 0.177 \\
\hline & Median & 0.266 & 0.107 & 0.154 & 0.077 & 0.018 & 0.138 \\
\hline & Standard Deviation & 0.389 & 0.340 & 0.285 & 0.360 & 0.292 & 0.337 \\
\hline & Count & 57 & 128 & 138 & 54 & 27 & 404 \\
\hline \multirow[t]{4}{*}{97.1} & Mean & 0.237 & 0.228 & 0.224 & 0.135 & 0.197 & 0.213 \\
\hline & Median & 0.234 & 0.193 & 0.186 & 0.076 & 0.163 & 0.178 \\
\hline & Standard Deviation & 0.294 & 0.329 & 0.371 & 0.262 & 0.303 & 0.328 \\
\hline & Count & 58 & 112 & 121 & 53 & 32 & 376 \\
\hline \multirow[t]{4}{*}{97.2} & Mean & 0.033 & 0.017 & -0.010 & -0.006 & -0.008 & 0.006 \\
\hline & Median & -0.017 & -0.009 & -0.028 & -0.027 & -0.047 & -0.024 \\
\hline & Standard Deviation & 0.265 & 0.306 & 0.247 & 0.331 & 0.289 & 0.285 \\
\hline & Count & 60 & 148 & 135 & 60 & 43 & 446 \\
\hline \multirow[t]{4}{*}{97.3} & Mean & 0.053 & 0.003 & 0.028 & -0.025 & -0.028 & 0.012 \\
\hline & Median & 0.060 & -0.003 & 0.036 & -0.028 & -0.016 & 0.015 \\
\hline & Standard Deviation & 0.193 & 0.289 & 0.221 & 0.228 & 0.302 & 0.249 \\
\hline & Count & 73 & 138 & 126 & 63 & 39 & 439 \\
\hline \multirow[t]{4}{*}{97.4} & Mean & -0.040 & -0.097 & -0.140 & -0.110 & -0.089 & -0.103 \\
\hline & Median & -0.033 & -0.090 & -0.147 & -0.135 & -0.109 & -0.114 \\
\hline & Standard Deviation & 0.248 & 0.239 & 0.227 & 0.280 & 0.257 & 0.246 \\
\hline & Count & 58 & 140 & 129 & 63 & 46 & 436 \\
\hline \multirow[t]{4}{*}{98.1} & Mean & -0.037 & -0.149 & -0.199 & -0.274 & -0.239 & -0.175 \\
\hline & Median & -0.051 & -0.179 & -0.212 & -0.266 & -0.261 & -0.208 \\
\hline & Standard Deviation & 0.328 & 0.233 & 0.267 & 0.188 & 0.287 & 0.271 \\
\hline & Count & 75 & 115 & 147 & 69 & 51 & 457 \\
\hline \multirow[t]{4}{*}{98.2} & Mean & 0.076 & -0.026 & 0.013 & 0.036 & 0.016 & 0.016 \\
\hline & Median & 0.048 & -0.011 & -0.011 & 0.037 & 0.006 & 0.004 \\
\hline & Standard Deviation & 0.312 & 0.273 & 0.303 & 0.337 & 0.264 & 0.298 \\
\hline & Count & 72 & 129 & 133 & 78 & 66 & 478 \\
\hline \multirow[t]{2}{*}{98.3} & Mean & 0.180 & 0.049 & 0.132 & 0.161 & 0.029 & 0.107 \\
\hline & Median & 0.181 & 0.024 & 0.056 & 0.075 & 0.017 & 0.054 \\
\hline
\end{tabular}




\begin{tabular}{|rlllllll|}
\hline \multirow{3}{*}{98.4} & Standard Deviation & 0.374 & 0.314 & 0.374 & 0.544 & 0.373 & 0.385 \\
& Count & 83 & 145 & 156 & 61 & 63 & 508 \\
& Mean & 0.157 & 0.112 & 0.194 & 0.190 & 0.237 & 0.165 \\
& Median & 0.062 & 0.079 & 0.141 & 0.133 & 0.238 & 0.118 \\
99.1 & Standard Deviation & 0.454 & 0.353 & 0.366 & 0.414 & 0.345 & 0.387 \\
& Count & 96 & 138 & 137 & 64 & 37 & 472 \\
& Mean & 0.225 & 0.105 & 0.069 & 0.054 & 0.074 & 0.107 \\
99.2 & Median & 0.158 & 0.076 & 0.001 & -0.033 & 0.005 & 0.054 \\
& Standard Deviation & 0.370 & 0.315 & 0.326 & 0.408 & 0.338 & 0.346 \\
& Count & 81 & 143 & 125 & 54 & 51 & 454 \\
99.3 & Mean & 0.469 & 0.317 & 0.289 & 0.136 & 0.185 & 0.306 \\
& Median & 0.437 & 0.230 & 0.134 & 0.075 & 0.112 & 0.221 \\
& Standard Deviation & 0.455 & 0.501 & 0.530 & 0.387 & 0.597 & 0.507 \\
& Count & 91 & 156 & 124 & 54 & 45 & 470 \\
& Mean & 0.619 & 0.467 & 0.448 & 0.732 & 0.438 & 0.518 \\
& Median & 0.533 & 0.397 & 0.328 & 0.547 & 0.473 & 0.408 \\
& Standard Deviation & 0.665 & 0.577 & 0.655 & 0.936 & 0.758 & 0.683 \\
\hline
\end{tabular}

${ }^{a}$ Stock transactions were made two months after the end of the SUE quarter for the first three quarters and three months after the end of the SUE quarter for the fourth quarter.

The strategy seems tempting, the question is: Are the spreads between the two portfolios statistically significant? This study examines whether excess returns (losses) indeed exist in the highest (lowest) SUE portfolios and if they are significant statistically. Excess return (loss) is defined as the difference between the mean return of each SUE portfolio and the mean return of all SUE portfolios in each investment period. Table 3 presents the excess mean returns (losses) by SUE category. As displayed in the table that the portfolio ranked the highest on SUE generated excess returns in 17 out of the 20 investment periods. Its overall mean of the excess returns is $6 \%$ with standard deviation of $6.5 \%$ and is significant at .0005 level. On the other hand, the portfolio ranked the lowest on SUE yielded excess losses in 15 out of the 20 investment periods. Its overall mean of excess losses is $3.3 \%$ with standard deviation of $6.2 \%$ and is significant at .05 level. The results suggest that arbitrage returns could be achieved by trading portfolios on the basis of past earnings surprises. If investors bought (short sold) the U.S. tech stocks with SUE $\geq$ 5 (SUE $\leq-5$ ) two or three months after the end of SUE quarter from 1994.4 to 1999.3 and rebalanced their portfolio holdings every three months, they would have earned a handsome arbitrage quarterly mean return of $9.3 \%$ $(=6 \%+3.3 \%)$ over the 5 -year investment horizon.

Table 3

Three-Month Holding Period Excess Returns ${ }^{\text {a }}$ By SUE Category, \# Of Analysts ${ }^{\mathrm{b}} \geq 3$

\begin{tabular}{|llllll|}
\hline SUE Quarter & SUE $\geq \mathbf{5}$ & $\mathbf{5}>\mathbf{S U E} \geq \mathbf{1}$ & $\mathbf{1}>\mathbf{S U E}>\mathbf{- 1}$ & $\mathbf{- 1} \geq \mathbf{S U E}>\mathbf{- 5}$ & $\mathbf{- 5} \geq \mathbf{S U E}$ \\
\hline 94.4 & 0.017 & -0.014 & 0.020 & 0.023 & -0.115 \\
95.1 & 0.051 & 0.019 & 0.019 & -0.115 & -0.088 \\
95.2 & 0.100 & -0.011 & 0.007 & -0.055 & -0.082 \\
95.3 & 0.089 & -0.016 & -0.025 & -0.033 & 0.060 \\
95.4 & 0.024 & -0.012 & -0.004 & 0.004 & 0.008 \\
96.1 & -0.003 & -0.019 & 0.049 & -0.064 & -0.007 \\
96.2 & 0.028 & 0.075 & -0.045 & 0.030 & -0.092 \\
96.3 & -0.097 & -0.026 & 0.040 & -0.004 & 0.090 \\
96.4 & 0.179 & -0.041 & -0.001 & -0.050 & -0.084 \\
97.1 & 0.025 & 0.016 & 0.012 & -0.077 & -0.015 \\
97.2 & 0.027 & 0.012 & -0.016 & -0.011 & -0.013 \\
97.3 & 0.042 & -0.009 & 0.017 & -0.037 & -0.040 \\
\hline
\end{tabular}




\begin{tabular}{|llllll|}
\hline 97.4 & 0.063 & 0.006 & -0.036 & -0.007 & 0.014 \\
98.1 & 0.139 & 0.026 & -0.023 & -0.098 & -0.063 \\
98.2 & 0.060 & -0.042 & -0.003 & 0.020 & 0.000 \\
98.3 & 0.073 & -0.058 & 0.025 & 0.054 & -0.077 \\
98.4 & -0.008 & -0.054 & 0.028 & 0.025 & 0.071 \\
99.1 & 0.119 & -0.002 & -0.038 & -0.053 & -0.032 \\
99.2 & 0.164 & 0.012 & -0.017 & -0.169 & -0.121 \\
99.3 & 0.101 & -0.051 & -0.070 & 0.214 & -0.080 \\
& & & & & -0.033 \\
Mean & 0.060 & -0.009 & -0.003 & -0.020 & 0.062 \\
Standard Deviation & 0.065 & 0.032 & 0.031 & 0.078 & $(2.416)^{*}$ \\
t- Statistics & $(4.130)^{* * *}$ & $(1.322)$ & $(0.465)$ & $(1.158)$ & \\
\hline
\end{tabular}

${ }^{\text {a }}$ Excess return=mean return of each SUE portfolio-mean return of all SUE portfolios in each investment period.

${ }^{\mathbf{b}} \#$ of analysts $=$ the number of financial analysts following the firm.

*** Significant at .0005 level.

* Significant at .05 level.

To see if the number of financial analysts following the firm plays any role in the relationship between SUE and the subsequent stock performance, the analysis is repeated in each of the three subgroups: group 1 contains the firms followed by no more than 5 analysts, group 3 with at least 10 analysts and group 2 contains the rest of the firms in the sample. The results are summarized in Tables 4, 5 and 6 . The portfolios that consistently outperformed the others across all three groups are the ones with SUE $\geq 5$. The mean excess returns are 3.8\% (t-statistics $=2.302$ ), $7.3 \%$ (t-statistics $=3.661$ ), and $9.5 \%$ (t-statistics $=4.449$ ) in groups 1,2 , and 3 respectively. The arbitrage trading strategy, taking a long position in the highest SUE portfolios and a short position in the lowest SUE portfolios is effective only in group 1. As is evidenced in Table 4, when the stocks are followed by three to five financial analysts, the 3.8\% mean excess return from investing in the highest SUE portfolios and the $4.3 \%$ mean excess loss from investing in the lowest SUE portfolios are statistically significant at .05 level. The arbitrage quarterly mean return equals $8.1 \%(=3.8 \%+4.3 \%)$ if investors adopted the trading strategy and repositioned their portfolio holdings on 3 month intervals over the 5-year study period. Tables 5 and 6 reveal that the arbitrage trading strategy is no longer effective when the stocks are followed by more than five analysts. As the stocks are monitored by more analysts in the market, more relevant information about the firm may be available to the public sooner and thus, arbitrage opportunities disappear. Nevertheless, when firms are followed by more than five analysts, investors could still gain more than $7 \%$ (significant at .005 level) quarterly mean excess return by investing in portfolios with SUE $\geq 5$ over the five-year investment horizon.

Table 4

Three-Month Holding Period Excess Returns By SUE Category, $3 \leq$ \# Of Analysts $<5$

\begin{tabular}{|llllll|}
\hline SUE Quarter & $\mathbf{S U E} \geq \mathbf{5}$ & $\mathbf{5}>\mathbf{S U E} \geq \mathbf{1}$ & $\mathbf{1}>\mathbf{S U E}>\mathbf{- 1}$ & $\mathbf{- 1} \geq \mathbf{S U E}>\mathbf{- 5}$ & $\mathbf{- 5} \geq \mathbf{S U E}$ \\
\hline 94.4 & -0.019 & -0.001 & -0.009 & -0.011 & -0.111 \\
95.1 & 0.004 & 0.066 & 0.046 & -0.136 & -0.069 \\
95.2 & 0.141 & 0.008 & 0.005 & -0.118 & -0.116 \\
95.3 & 0.085 & -0.007 & -0.038 & -0.084 & 0.030 \\
95.4 & 0.007 & 0.014 & -0.018 & 0.034 & 0.038 \\
96.1 & -0.012 & -0.027 & 0.086 & -0.102 & -0.007 \\
96.2 & -0.062 & 0.088 & -0.102 & 0.004 & -0.138 \\
96.3 & -0.118 & -0.016 & -0.016 & -0.010 & 0.062 \\
96.4 & 0.159 & -0.052 & -0.028 & -0.077 & -0.127 \\
97.1 & 0.042 & -0.005 & 0.014 & -0.114 & -0.086 \\
97.2 & 0.029 & 0.028 & 0.001 & 0.023 & -0.061 \\
\hline
\end{tabular}




\begin{tabular}{|llllll|}
\hline 97.3 & 0.035 & -0.015 & -0.005 & -0.076 & -0.060 \\
97.4 & 0.045 & -0.038 & -0.070 & -0.010 & 0.029 \\
98.1 & 0.162 & -0.014 & -0.046 & -0.108 & -0.083 \\
98.2 & 0.083 & -0.013 & 0.006 & 0.004 & -0.015 \\
98.3 & -0.024 & -0.046 & 0.011 & 0.056 & -0.076 \\
98.4 & -0.009 & -0.042 & 0.020 & -0.004 & 0.056 \\
99.1 & 0.087 & -0.016 & -0.027 & -0.035 & -0.028 \\
99.2 & 0.114 & 0.000 & -0.146 & -0.165 & 0.214 \\
99.3 & 0.007 & -0.011 & -0.053 & 0.320 & -0.043 \\
Mean & & & & & 0.082 \\
Standard Deviation & 0.073 & -0.005 & -0.018 & -0.030 & $(2.331)^{*}$ \\
t- Statistics & $(2.302)^{*}$ & 0.035 & 0.050 & 0.104 & $(1.314)$ \\
\hline
\end{tabular}

* Significant at .05 level.

Table 5

Three-Month Holding Period Excess Returns By Sue Category, $5 \leq \#$ Of Analysts $<10$

\begin{tabular}{|c|c|c|c|c|c|}
\hline SUE Quarter & SUE $\geq 5$ & $5>$ SUE $\geq 1$ & $1>$ SUE > -1 & $-1 \geq$ SUE $>-5$ & $-5 \geq$ SUE \\
\hline 94.4 & -0.032 & -0.003 & 0.027 & -0.004 & -0.127 \\
\hline 95.1 & 0.122 & -0.062 & -0.019 & -0.173 & -0.075 \\
\hline 95.2 & 0.021 & -0.039 & 0.018 & 0.035 & -0.024 \\
\hline 95.3 & 0.111 & -0.035 & -0.030 & 0.000 & 0.290 \\
\hline 95.4 & 0.076 & -0.036 & 0.073 & -0.153 & -0.041 \\
\hline 96.1 & -0.027 & -0.078 & -0.060 & -0.022 & 0.050 \\
\hline 96.2 & 0.116 & 0.004 & 0.031 & 0.068 & 0.031 \\
\hline 96.3 & -0.075 & -0.029 & 0.056 & -0.046 & 0.127 \\
\hline 96.4 & 0.289 & -0.073 & 0.064 & 0.109 & 0.175 \\
\hline 97.1 & -0.035 & 0.099 & -0.018 & -0.042 & 0.131 \\
\hline 97.2 & 0.074 & 0.021 & 0.021 & -0.008 & 0.165 \\
\hline 97.3 & 0.059 & -0.026 & 0.033 & -0.057 & 0.083 \\
\hline 97.4 & 0.067 & 0.037 & -0.019 & -0.029 & -0.002 \\
\hline 98.1 & 0.122 & 0.034 & -0.032 & -0.122 & -0.096 \\
\hline 98.2 & -0.003 & -0.126 & -0.028 & 0.045 & 0.001 \\
\hline 98.3 & 0.106 & -0.117 & 0.068 & 0.017 & -0.110 \\
\hline 98.4 & 0.002 & -0.073 & 0.039 & 0.009 & 0.022 \\
\hline 99.1 & 0.201 & -0.029 & -0.051 & -0.068 & -0.023 \\
\hline 99.2 & 0.091 & -0.032 & 0.114 & -0.086 & -0.088 \\
\hline 99.3 & 0.163 & -0.038 & 0.003 & 0.271 & -0.447 \\
\hline Mean & 0.073 & -0.030 & 0.014 & -0.013 & 0.002 \\
\hline Standard Deviation & 0.089 & 0.053 & 0.046 & 0.097 & 0.152 \\
\hline t- Statistics & $(3.661)^{* *}$ & $(2.527)^{*}$ & $(1.393)$ & $(0.588)$ & $(0.062)$ \\
\hline
\end{tabular}

** Significant at .005 level.

* Significant at .05 level. 
The weak form of efficient-market hypothesis states that one cannot make easy profits by acting on past information. That is, the market has no memory and knowing the past doesn't help in generating future returns. The results presented in this study seem to suggest otherwise. Is the market really inefficient in its weak form? Instead of refuting the hypothesis, one possible explanation for the results in this study is explored. To see if the size and sign of past SUE might be indicative of the size and sign of future SUE, the serial correlations of SUEs over the quarters of $1994.4-1999.2$ are calculated and summarized in Table 7. It is interesting to note that the SUE in quarter Q is positively correlated with the SUE in the subsequent four quarters, Q+1, Q+2, Q+3 and Q+4, with the mean correlation coefficient equaling $.349, .255, .226$ and .180 respectively. Figure 2 displays that the coefficients of correlation are positive in all paired quarters, thus the stock with high SUE tends to have high SUE in subsequent quarters and vice versa. Trading on the basis of previous quarter's SUE is profitable as it is directly correlated with the SUE in the subsequent quarter. It is possible that trading on past SUE won't be effective when the previous quarter's SUE is no longer strongly correlated with the subsequent quarter's SUE in the future.

Table 6

Three-Month Holding Period Excess Returns By SUE Category, \# Of Analysts $\geq 10$

\begin{tabular}{|c|c|c|c|c|c|}
\hline SUE Quarter & SUE $\geq 5$ & $5>$ SUE $\geq 1$ & $1>\mathrm{SUE}>-1$ & $-1 \geq$ SUE $>-5$ & $-5 \geq$ SUE \\
\hline 94.4 & 0.171 & -0.060 & 0.079 & 0.152 & -0.066 \\
\hline 95.1 & 0.117 & -0.054 & 0.012 & -0.010 & -0.192 \\
\hline 95.2 & 0.046 & -0.037 & 0.001 & 0.001 & -0.013 \\
\hline 95.3 & 0.062 & -0.022 & 0.027 & 0.060 & 0.022 \\
\hline 95.4 & 0.012 & -0.063 & -0.041 & 0.024 & -0.054 \\
\hline 96.1 & 0.128 & 0.135 & 0.123 & -0.007 & -0.047 \\
\hline 96.2 & 0.244 & 0.079 & 0.050 & 0.074 & -0.032 \\
\hline 96.3 & -0.001 & -0.061 & 0.195 & 0.077 & 0.189 \\
\hline 96.4 & 0.143 & 0.043 & -0.016 & -0.138 & -0.061 \\
\hline 97.1 & 0.054 & -0.015 & 0.088 & 0.062 & 0.021 \\
\hline 97.2 & -0.039 & -0.070 & -0.122 & -0.179 & na \\
\hline 97.3 & 0.029 & 0.050 & 0.043 & 0.170 & 0.059 \\
\hline 97.4 & 0.124 & 0.080 & 0.034 & 0.069 & -0.041 \\
\hline 98.1 & 0.085 & 0.104 & 0.055 & -0.023 & 0.081 \\
\hline 98.2 & 0.067 & -0.011 & 0.008 & 0.041 & 0.078 \\
\hline 98.3 & 0.242 & 0.001 & 0.012 & 0.152 & 0.009 \\
\hline 98.4 & -0.014 & -0.055 & 0.032 & 0.173 & 0.252 \\
\hline 99.1 & 0.100 & 0.048 & -0.046 & -0.077 & -0.059 \\
\hline 99.2 & 0.330 & 0.069 & 0.040 & -0.300 & 0.052 \\
\hline 99.3 & 0.007 & -0.011 & -0.053 & 0.320 & 0.120 \\
\hline Mean & 0.095 & 0.007 & 0.026 & 0.032 & 0.017 \\
\hline Standard Deviation & 0.096 & 0.064 & 0.068 & 0.138 & 0.101 \\
\hline t- Statistics & $(4.449) * * *$ & $(0.527)$ & $(1.722)$ & $(1.041)$ & $(0.719)$ \\
\hline
\end{tabular}

na $=$ not available

*** Significant at .0005 level. 
Table 7

Serial Correlation Coefficient of SUE, By Quarter

\begin{tabular}{|lllll|}
\hline $\mathbf{Q}$ & $\mathbf{Q + 1}$ & $\mathbf{Q + 2}$ & $\mathbf{Q + 3}$ & $\mathbf{Q + 4}$ \\
\hline 94.4 & 0.341 & 0.239 & 0.180 & 0.278 \\
95.1 & 0.403 & 0.230 & 0.305 & 0.191 \\
95.2 & 0.299 & 0.329 & 0.274 & 0.214 \\
95.3 & 0.295 & 0.269 & 0.121 & 0.162 \\
95.4 & 0.274 & 0.119 & 0.275 & 0.203 \\
96.1 & 0.364 & 0.251 & 0.164 & 0.096 \\
96.2 & 0.429 & 0.330 & 0.145 & 0.197 \\
96.3 & 0.488 & 0.141 & 0.164 & 0.065 \\
96.4 & 0.299 & 0.202 & 0.227 & 0.161 \\
97.1 & 0.381 & 0.272 & 0.286 & 0.292 \\
97.2 & 0.257 & 0.224 & 0.189 & 0.086 \\
97.3 & 0.166 & 0.258 & 0.169 & 0.088 \\
97.4 & 0.338 & 0.356 & 0.294 & 0.215 \\
98.1 & 0.307 & 0.327 & 0.282 & 0.130 \\
98.2 & 0.421 & 0.276 & 0.341 & 0.216 \\
98.3 & 0.427 & 0.284 & 0.217 & 0.289 \\
98.4 & 0.397 & 0.262 & 0.203 & \\
99.1 & 0.466 & & & 0.180 \\
99.2 & 0.275 & & & \\
Mean & 0.349 & 0.255 & 0.226 & \\
\hline
\end{tabular}

$\mathrm{Q}=$ the SUE quarter

$\mathrm{Q}+\mathrm{j}=\mathrm{j}$ quarter(s) after the SUE quarter, $\mathrm{j}=1,2,3,4$.

Figure 2

Serial Correlation Coefficient Of SUE

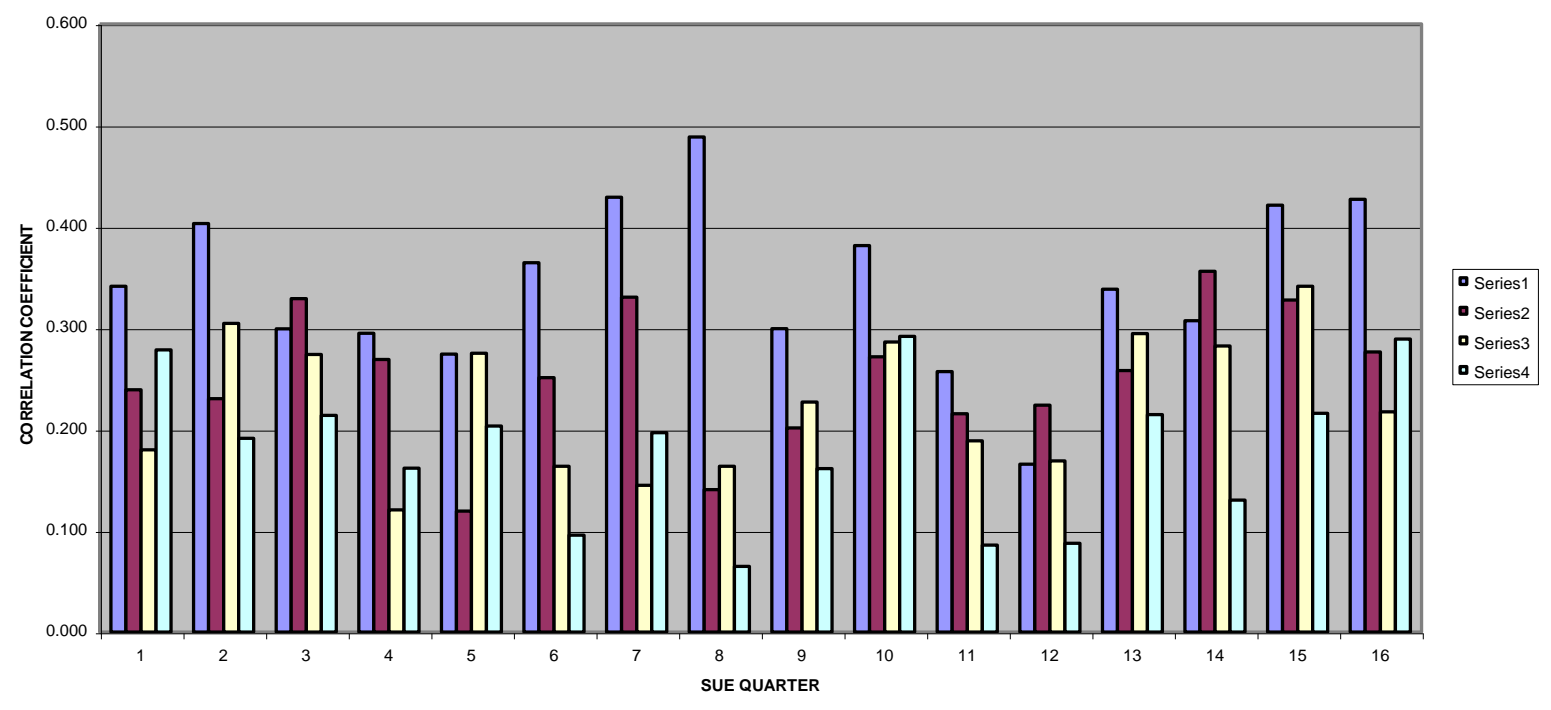

Series 1 = Correlation coefficient between SUE in Q and SUE in Q+1

Series 2 = Correlation coefficient between SUE in Q and SUE in Q+2

Series 3 = Correlation coefficient between SUE in Q and SUE in Q+3

Series 4 = Correlation coefficient between SUE in Q and SUE in Q+4 


\section{Summary And Conclusions}

This study shows that unexpected earnings are useful in identifying portfolios that yield excess returns in the U.S. tech sector. The highest SUE portfolios outperformed the lowest SUE portfolios in terms of both mean and median returns in every single quarter from 1995.2 to 2000.1 when the portfolios were invested at the ending month of the SUE quarter for the quarters of 1995.1 to 1999.4. As SUE information is not available at the end of the SUE quarter, accurately predicting SUE is extremely rewarding for fund managers and investors in the U.S. tech stock market. In addition, the study finds that arbitrage returns could be achieved by trading portfolios on the basis of past earnings surprises. If investors bought (short sold) the U.S. tech stocks with SUE $\geq 5$ (SUE $\leq-5$ ) two or three months after the end of SUE quarter from 1994.4 to 1999.3 and rebalanced their portfolio holdings every three months, they would have earned a handsome arbitrage quarterly mean return of $9.3 \%$ over the 5 -year investment horizon. The study demonstrates that this trading strategy is most effective when the firms are followed by three to five financial analysts. When the stocks are widely monitored by analysts in the market, more relevant information about the stock may be available to the public sooner and thus, arbitrage opportunities disappear. Nonetheless, when firms are followed by more than five analysts, investors could still gain more than 7\% (significant at .005 level) quarterly mean excess return by investing in portfolios with SUE $\geq 5$ over the five-year investment horizon. Finally, the study suggests that trading on the basis of previous quarter's SUE is profitable as it is directly correlated with the SUE in the subsequent quarter. It is possible that trading on past SUE won't be effective when the previous quarter's SUE is no longer strongly correlated with the subsequent quarter's SUE in the future.

\section{References}

1. Bird, R., B. McElwee, and J. McKinnon. "A Global Perspective of Analysts' Earnings Forecasts." The Journal of Investing, Winter 2000, pp. 76-82.

2. Bird, R. and J. McKinnon. "Changes in the Behavior of Earnings Surprise: International Evidence and Implications." The Journal of Investing, Fall 2001, pp. 19-32.

3. Brown, L. D. “Can ESP Yield Abnormal Returns?” Journal of Portfolio Management, Summer 1997, pp. 36-43.

4. Brown, L. D. and S. W. Jeong “Profiting from Predicting Earnings Surprise.” Journal of Financial Statement Analysis, Winter 1998, pp. 57-66.

5. Conroy, R.M., K.M. Eades, and R.S. Harris. "A Test of the Relative Pricing Effects of Dividends and Earnings: Evidence from Simultaneous Announcements in Japan.” Journal of Finance, June 2000, pp. 11991227.

6. Dische, A. and H. Zimmermann. "Consensus Forecasts of Corporate Earnings Changes and the Performance of Swiss Stocks." The Journal of Investing, Spring 1999, pp. 19- 26.

7. Herzberg, M. M., J. Guo, and L. D. Brown. "Enhancing Earnings Predictability Using Individual Analyst Forecasts." The Journal of Investing, Summer 1999, pp. 15-24.

8. Hsu, H. C. "Earnings Surprises and Stock Returns: Some Evidence from Asia/Pacific and Europe." Business Quest, 2001.

9. Jones, C.P., R.J. Rendleman, and H.A. Latane. "Stock Returns and SUEs During the 1970s." Journal of Portfolio Management, Winter 1984, pp. 18-22.

10. Levis, M. and M. Liodakis. "Contrarian Strategies and Investor Expectations: the U.K. Evidence." Financial Analysts Journal, September/October 2001, pp. 43-56.

11. Latane, H. A. and C. P. Jones. "Standardized Unexpected Earnings - a progress report." Journal of Finance, December 1977, pp. 1457-1465.

12. Latane, H. A. and C. P. Jones. "Standardized Unexpected Earnings - 1971-77." Journal of Finance, June 1979, pp.717-724.

13. Mozes, H.A. "The Role of Value in Strategies Based on Anticipated Earnings Surprise." Journal of Portfolio Management, Winter 2000, pp. 54-62.

14. Sultan, A.T. "Earnings Surprise in Japan." The Journal of Investing, winter 1994, pp. 32-38. 